\title{
Electrochemical study of $\beta$-nitrostyrene derivatives: steric and electronic effects on their electroreduction
}

\author{
J.A. Squella ${ }^{\text {a,* }}$, J.C. Sturm ${ }^{\text {a }}$ B. Weiss-Lopez ${ }^{\text {b }}$, M. Bontá ${ }^{\text {a }}$ L.J. Núñez-Vergara ${ }^{\text {a }}$ \\ a Bioelectrochemistry Laboratory, Chemical and Pharmaceutical Sciences Faculty, Department of Organic Chemistry, \\ University of Chile. PO Box 233, Santiago 1, Chile \\ ${ }^{\mathrm{b}}$ Chemistry Department, Sciences Faculty, University of Chile, Santiago 1, Chile
}

\begin{abstract}
The electrochemical reduction of a series of $\beta$-nitrostyrene and $\beta$-methyl- $\beta$-nitrostyrene derivatives by tast and differential pulse polarography and cyclic voltammetry over a wide $\mathrm{pH}$ range was studied. The reduction potentials are sensitive to the electronic properties of the para-substituent and to the substitution at $\mathrm{C} \beta$. An increase in the electron-donor properties of the substituent at the para position makes the reduction potential more negative. On the other hand, the reduction potential shifts several tens of millivolts towards more negative potentials on going from $\beta$-nitrostyrene to $\beta$-methyl- $\beta$-nitrostyrene derivatives, due to the decrease in conjugation with the increase in the $\mathrm{C} 1-\mathrm{C} \alpha$ torsion angle. A linear correlation between the calculated electronic barrier and the half-wave potential was observed. Furthermore, a linear correlation between the Hammett $\sigma_{\mathrm{p}}$ substituent constant and the half-wave potential also was observed, demonstrating that the electrochemical behaviour of these derivatives depends primarily on molecular structure and electron density distribution in a way similar to rates and equilibrium of homogeneous chemical reaction. The $\beta$-nitrostyrenes studied illustrate nicely the effects of steric and electronic effects on electrochemical reactions.
\end{abstract}

Keywords: $\beta$-Nitrostyrene derivatives; Electroreduction; Cyclic voltammetry

\section{Introduction}

Over 50 years ago the fungistatic action and toxicity towards insects of $\beta$-nitrostyrene compounds was observed [1-3]; consequently, today they are used in some pesticide formulations [4]. Other studies have shown that a number of $\beta$-nitrostyrene derivatives are cytotoxic and some of them inhibit Krebs II ascitic carcinoma in mice $[5,6]$. The cytotoxity of these substances has been correlated with the electrophilicity $[7,8]$ and the Hückel bond index of the nitrovinyl bond [9]. An important number of pharmacologically active substances have an aromatic nitro group in their molecular structure, which accounts for their biological activity.

E-mail address: asquella@1l.ciq.uchile.cl (J.A. Squella)
The pattern of action is a consequence of the ability of these drugs to accept electrons, which makes the reduction of the nitro group possible, being metabolised to the corresponding amines via the nitro radical anion, nitroso and hydroxylamine intermediates. It is known that aromatic and heterocyclic nitro compounds can be reduced by nitro reductases such as NADPH-cytochrome- $c$ reductase [10-12] and cytochrome P-450 [13]. On the other hand, the enzymatic reduction of aliphatic nitro compounds has not been reported, the enzymatic reduction of $\beta$-nitrostyrene [14] being an exception.

From the electrochemical point of view, several papers on the electrochemical study of aromatic, heterocyclic and aliphatic nitro compounds have been published [15-20]. However, the $\beta$-nitrostyrenes present a special position between aromatic and aliphatic nitro 
compounds, since the nitro compound is distant from the aromatic ring but conjugated with an ethylenic double bond. Furthermore, the $\beta$-nitrostyrenes attracted our attention because these represent one of the simplest molecular skeletons where long-distance transmission of substituent effects through aromatic systems can be observed. Based on this, it is interesting to study the electrochemical reduction of these compounds.

The electrochemistry of $\beta$-nitrostyrene derivatives is an unexplored field of research. There are only two published papers relating to the polarography of $\beta$-nitrostyrene. Masui and Sayo [21] have proposed that the reduction of $\beta$-nitrostyrene occurs in two steps. The first step is a four-electron reduction that yields phenylacetaldoxime followed by the two-electron reduction of the $\mathrm{C}=\mathrm{N}$ bond to produce the hydroxylamine derivative. Holleck et al. [22] reported that in acidic media the compound behaves like an aromatic nitro compound, but under alkaline conditions a conversion to a polarographically inactive acinitro form is observed and also other time-dependent secondary reactions like polymerization and hydrolytic ruptures are possible.

The present study deals with the electrochemical properties of a comprehensive series of para-substituted $\beta$-nitrostyrenes (NS) and $\beta$-methyl- $\beta$-nitrostyrenes (MNS) (Fig. 1), in order to report on substituent effects in the reduction of the nitro group of this series. In this article we concentrate on two aspects of the influence of the substituent. First, we discuss the effects of the substituent at the para position of the aromatic ring on the reduction potential of the nitro group. Second, we discuss the substitution of the $\beta$-proton by a methyl group in order to study the influence of coplanarity between the aromatic ring and the ethylenic double bond on the reduction of the nitro group. There are large amounts of work reported on correlation between spectroscopic observations and substituent effects in styrene derivatives [23-27]; however, despite the special electronic characteristics of this type of compound, no attempt has been made to find a correlation with the electrochemical parameters.

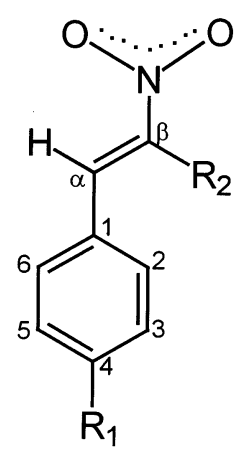

Fig. 1. Molecular structure of $\beta$-nitrostyrene and $\beta$-methyl- $\beta$-nitrostyrene derivatives.

\section{Experimental}

\subsection{Chemicals}

The substituted nitrostyrene derivatives were prepared following previously reported synthetic routes [28,29].

Stock solutions $\left(1 \times 10^{-3} \mathrm{M}\right)$ of the different compounds were prepared in $\mathrm{CH}_{3} \mathrm{OH}$. The polarographic working solutions were prepared by diluting $1 \mathrm{ml}$ of the stock solution with $15 \mathrm{ml}$ of supporting electrolyte to obtain a final concentration of $6.25 \times 10^{-5} \mathrm{M}$. Solutions for cyclic voltammetry were prepared by weighing an adequate quantity of nitrostyrene derivative in order to obtain a final concentration of $1 \times 10^{-3} \mathrm{M}$ in the supporting electrolyte. The supporting electrolyte was a Britton-Robinson buffer $\left(0.04 \mathrm{M}\right.$ each of $\mathrm{H}_{3} \mathrm{PO}_{4}$, $\mathrm{CH}_{3} \mathrm{COOH}$, and $\mathrm{H}_{3} \mathrm{BO}_{3}$ ) with $20 \%$ ethanol to enhance the solubility of the nitrostyrenes. The $\mathrm{pH}$ was adjusted using $\mathrm{HCl}$ or $\mathrm{NaOH}$ solutions. For the experiments in aprotic media, $0.1 \mathrm{M}$ TBAP as supporting electrolyte in $100 \%$ DMF was used.

\subsection{Equipment}

Tast, differential pulse polarograms and cyclic voltammograms were performed with a Metrohm ${ }^{\circledR} 693$ VA processor and 694 VA stand equipped with a $\mathrm{Ag}|\mathrm{AgCl}| \mathrm{KCl}_{\text {(sat.) }}$ reference electrode, platinum counter electrode and a Metrohm multimode mercury electrode. The recorded curves were transferred to a computer for measurement and treatment.

The temperature of the working solutions was controlled at $20^{\circ} \mathrm{C}$ and purified nitrogen was used for oxygen displacement. Also electrochemical measurements were carried out in an Inelecsa ${ }^{\circledR}$ assembly similar to that described previously [18].

Spectrophotometric determinations were carried out on a Unicam ${ }^{\circledR}$ UV-2 scanning spectrophotometer with Vision ${ }^{\circledR}$ software for acquisition and treatment.

Coulometry and potential controlled electrolysis were performed with a BAS CV-50W voltammetric analyzer equipped with a BAS MF-1056 bulk electrolysis cell. A reticulated vitreous carbon electrode was used as the working electrode. The electrolyte was BrittonRobinson buffer, $20 \%$ in EtOH at $\mathrm{pH}$ 2. The applied potential was $-400 \mathrm{mV}$ versus $\mathrm{Ag} \mid \mathrm{AgCl}$. A nitrogen stream and stirring were maintained in the solution during the electrolysis.

\section{Results and discussion}

All the compounds synthesized (Fig. 1) were subjected to polarographic study in the tast and differential pulse modes and to a cyclic voltammetric study in order to characterize their electrochemical behaviour. 


\section{II $\mu \mathrm{A}$}
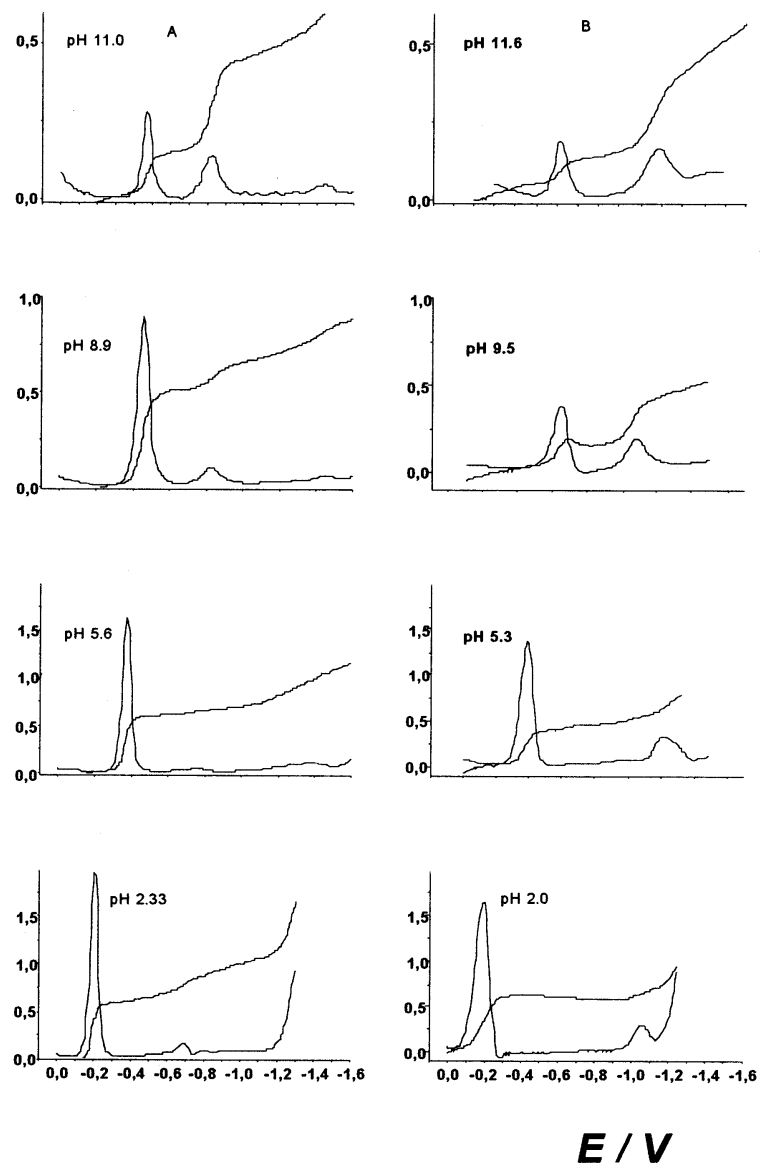

Fig. 2. Differential pulse and tast polarograms of (A) $\beta$-nitrostyrene and (B) $p$-OH- $\beta$-nitrostyrene at different $\mathrm{pH}$ values in aqueous media.

\subsection{Polarography}

When nitrostyrene derivatives were subjected to polarographic experiments, all the compounds were capable of being reduced at a mercury electrode in both differential pulse and tast polarographic modes. All the compounds produce one main peak (or wave) that remains present at all $\mathrm{pH}$ values. Furthermore, two other signals are also observed, one of them only appearing at low $\mathrm{pH}$ and the other one at high $\mathrm{pH}$. In Fig. 2 we show the polarographic response of $\beta$-nitrostyrene and $p$-hydroxy- $\beta$-nitrostyrene as an example of the polarographic behaviour of all the nitrostyrene derivatives studied.

In the case of the dinitro compounds, the behaviour is rather different due to the presence of two nitro groups with different electrophilic character. Consequently, each nitro group produces a different signal, but at very similar potentials, causing overlapping.

The polarographic behaviour of all the compounds is strongly $\mathrm{pH}$ dependent. As a way to quantify the $\mathrm{pH}$ effect on the polarographic behaviour, the half-wave potential, $E_{1 / 2}$, and the limiting current, $I_{\mathrm{d}}$, were measured. This behaviour is shown in Fig. 3 for the case of $\beta$-nitrostyrene. However, all the compounds studied follow similar polarographic behaviour with $\mathrm{pH}$. From this behaviour we can distinguish clearly a main wave that appears at all $\mathrm{pH}$ values. This wave appears to be $\mathrm{pH}$-dependent below $\mathrm{pH}$ 8.5. In alkaline media $(\mathrm{pH}>$ 8.5 ), the half-wave potentials (or peak potentials) are independent of $\mathrm{pH}$, showing that no protonation is involved before or in the rate-determining step. In the $\mathrm{pH}$-dependent region we can observe a slight break at approximately $\mathrm{pH} 3.5$ for all compounds. The slope of the $E_{1 / 2}$ versus $\mathrm{pH}$ lines in the $4<\mathrm{pH}<8$ zone are shown in Table 1 for all compounds. From these results we have calculated a $\Delta E_{1 / 2} / \Delta \mathrm{pH}$ mean value of $50.28 \pm$ $1.49 \mathrm{mV}$ for the $\beta$-nitrostyrene series and $55.00 \pm 6.27$ $\mathrm{mV}$ for the $\beta$-methyl- $\beta$-nitrostyrene series. From these results we can affirm that $\Delta E_{1 / 2} / \Delta \mathrm{pH}$ values are practically similar for all compounds.

The relationship between the limiting current of the main wave with $\mathrm{pH}$ is also shown in Fig. 3. In this figure it is observed that the limiting current is $\mathrm{pH}$ independent between $\mathrm{pH} 1.5$ and 8 , showing characteristic behaviour for diffusion-controlled limiting cur-
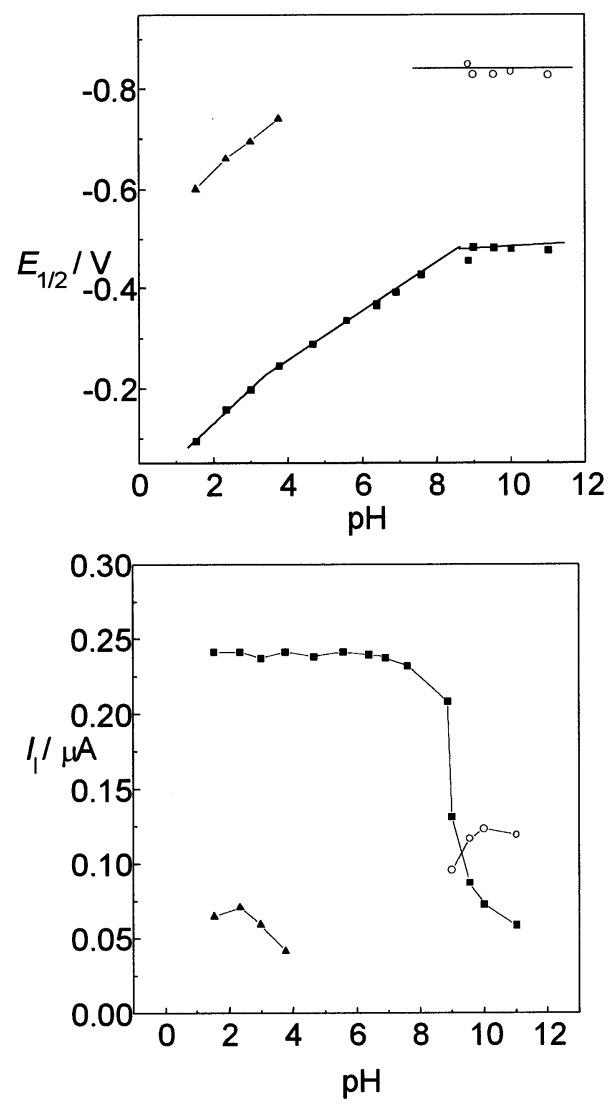

Fig. 3. Half-wave potential and limiting current dependence on $\mathrm{pH}$ for $6.25 \times 10^{-5} \mathrm{M} \beta$-nitrostyrene in Britton-Robinson buffer, $20 \%$ EtOH. 
Table 1

Polarographic and coulometric parameters for $\beta$-nitrostyrenes and $\beta$-methyl- $\beta$-nitrostyrenes

\begin{tabular}{|c|c|c|c|c|c|c|c|c|c|c|}
\hline \multirow[t]{2}{*}{ Compound } & \multirow[t]{2}{*}{$\mathrm{R}_{1}$} & \multirow[t]{2}{*}{$\mathrm{R}_{2}$} & \multicolumn{2}{|c|}{$E_{1 / 2}(\mathrm{pH} 3) / \mathrm{V}$} & \multicolumn{2}{|c|}{$E_{1 / 2}(\mathrm{pH} 10) / \mathrm{V}$} & \multirow{2}{*}{$\begin{array}{l}\Delta E_{1 / 2} / \Delta \mathrm{pH}(\mathrm{pH} 4-7) \\
\text { 1st wave }\end{array}$} & \multirow{2}{*}{$\begin{array}{l}I_{\mathrm{d}} / c(\mathrm{pH} 3) / \mathrm{AM}^{-1} \\
1 \text { st wave }\end{array}$} & \multirow[t]{2}{*}{$n^{\prime \mathrm{a}}$} & \multirow[t]{2}{*}{$n^{\prime \prime \mathrm{b}}$} \\
\hline & & & $1^{\text {st }}$ wave & $2^{\text {nd }}$ and $3^{\text {rd }}$ waves & $1^{\text {st }}$ wave & $2^{\text {nd }}$ and $3^{\text {rd }}$ waves & & & & \\
\hline Ia & $-\mathrm{H}$ & $-\mathrm{H}$ & -0.200 & -0.698 & -0.483 & -0.855 & 0.0490 & 3.98 & 3.37 & 3.69 \\
\hline $\mathrm{Ib}$ & $-\mathrm{H}$ & $-\mathrm{CH}_{3}$ & -0.230 & -1.114 & -0.613 & -0.866 & 0.0608 & 4.41 & 3.73 & 3.93 \\
\hline IIa & $-\mathrm{CH}_{3}$ & $-\mathrm{H}$ & -0.215 & -0.915 & -0.535 & -0.890 & 0.0503 & 3.87 & 3.27 & 3.95 \\
\hline $\mathrm{IIb}$ & $-\mathrm{CH}_{3}$ & $-\mathrm{CH}_{3}$ & -0.250 & -1.108 & -0.639 & -0.901 & 0.0641 & 4.96 & 4.21 & 4.08 \\
\hline IIIa & $-\mathrm{OCH}_{3}$ & $-\mathrm{H}$ & -0.217 & -0.346 & -0.553 & -0.927 & 0.0518 & 4.0 & 3.38 & 3.75 \\
\hline IVa & $-\mathrm{OH}$ & $-\mathrm{H}$ & -0.212 & -0.386 & -0.622 & -1.048 & 0.0530 & 4.85 & 4.11 & 4.02 \\
\hline $\mathrm{IVb}$ & $-\mathrm{OH}$ & $-\mathrm{CH}_{3}$ & -0.269 & -0.366 & -0.687 & -1.057 & 0.0567 & 5.29 & 4.48 & 4.10 \\
\hline $\mathrm{Va}$ & $\mathrm{N}\left(\mathrm{CH}_{3}\right)_{2}$ & $-\mathrm{H}^{3}$ & -0.265 & -0.896 & -0.660 & -0.911 & 0.0515 & 6.48 & 5.49 & 3.80 \\
\hline $\mathrm{Vb}$ & $\mathrm{N}\left(\mathrm{CH}_{3}\right)_{2}$ & $-\mathrm{CH}_{3}$ & -0.292 & -1.112 & -0.690 & - & 0.0536 & 6.51 & 5.51 & 4.16 \\
\hline VIa & $-\mathrm{NO}_{2}$ & $-\mathrm{H}$ & -0.123 & $-0.254(-0.333)$ & -0.399 & $-0.683(-1.371)$ & 0.0486 & 4.94 & 4.18 & 7.40 \\
\hline VIb & $-\mathrm{NO}_{2}$ & $-\mathrm{CH}_{3}$ & -0.151 & $-0.260(-0.373)$ & -0.405 & -0.670 & 0.0453 & 5.36 & 4.54 & 7.70 \\
\hline VIIa $^{\mathrm{c}}$ & $-\mathrm{OCH}_{3}$ & $-\mathrm{H}$ & -0.206 & -0.923 & -0.508 & -0.874 & 0.0496 & 4.13 & 3.5 & 3.85 \\
\hline VIII $^{c}$ & $-\mathrm{OCH}_{3}$ & $-\mathrm{CH}_{3}$ & -0.237 & -0.795 & -0.643 & -0.876 & 0.0500 & 6.11 & 5.17 & 4.05 \\
\hline VIII $^{\mathrm{d}}$ & - & - & -0.32 & -0.946 & -0.682 & -0.849 & 0.0605 & 4.72 & 4.0 & 4.02 \\
\hline $\mathrm{IX}^{\mathrm{e}}$ & - & - & -0.95 & - & -0.950 & - & - & - & - & \\
\hline
\end{tabular}

a $n^{\prime}=$ Number of electrons obtained by polarography using the four-electron reduction of nitrobenzene as standard.

b $n^{\prime \prime}=$ Number of electrons obtained by coulometry.

c 3,4,5-Trimethoxy derivatives.

${ }^{\mathrm{d}}$ Nitrobenzene.

${ }^{\mathrm{e}}$ Nitromethane. 


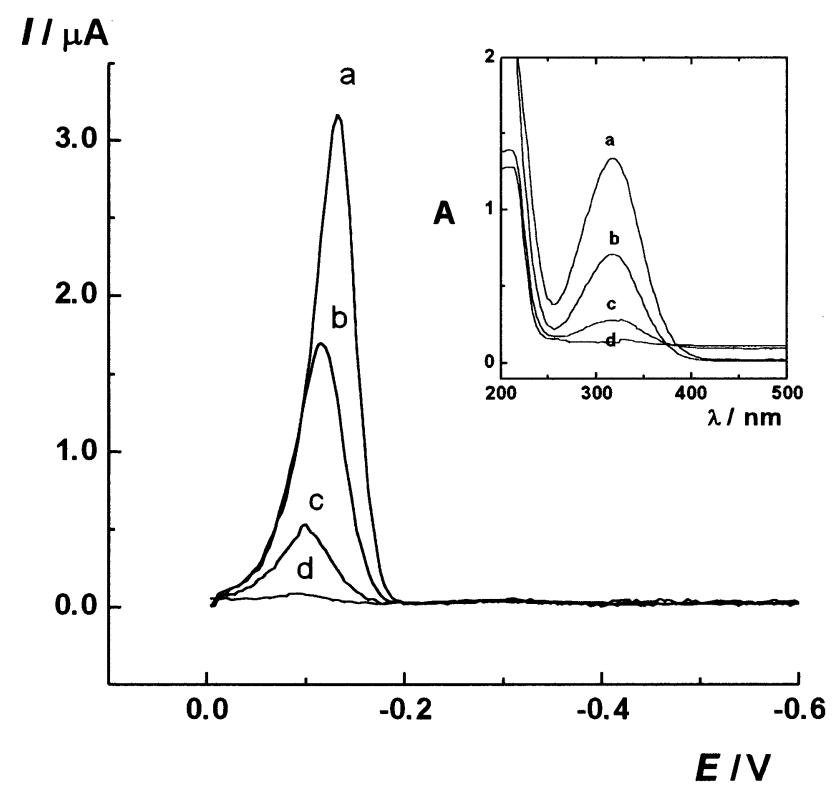

Fig. 4. Evolution of DP polarograms of $1.8 \times 10^{-4} \mathrm{M}$ of $\beta$-methyl- $\beta$ nitrostyrene electrolyzed at different times: (a) 0; (b) 5; (c) 10 and (d) 15 min. Inset: evolution of the UV-spectra at the same electrolysis times. Applied potential: $-400 \mathrm{mV}$.

rents. A comparison between the main wave in the tast polarograms of solutions of the same concentration and $\mathrm{pH}$ for all nitrostyrene derivatives and nitrobenzene (Table 1) shows that the ratio of limiting currents is close to 1 . Coulometry experiments confirm these experimental findings producing a value near 4 for the number of exchanged electrons. For the case of the dinitro compounds a value near 8 , due to both overlapped signals, was obtained. Controlled potential electrolyses (CPE) at $-400 \mathrm{mV}$ versus $\mathrm{Ag} \mid \mathrm{AgCl}$ of all compounds were performed and followed by polarography and UV-spectrophotometry. In Fig. 4, the evolution of both differential pulse polarograms and the UV-spectra at different electrolysis times are shown. The above experiments confirm that the main wave is due to a four-electron, four-proton reduction as for nitrobenzene, according to the following equation:

$$
\begin{gathered}
\mathrm{R}_{1}-\phi-\mathrm{CH}=\mathrm{CR}_{2}-\mathrm{NO}_{2}+4 \mathrm{e}^{-}+4 \mathrm{H}^{+} \rightarrow \mathrm{R}_{1}-\phi-\mathrm{CH}=\mathrm{CR}_{2} \\
-\mathrm{NHOH}+\mathrm{H}_{2} \mathrm{O}
\end{gathered}
$$

At high $\mathrm{pH}$ (approximately $>8.5$, depending on the compound) the main wave (or peak) is split in two new waves. In Fig. 5 the gradual splitting of the main wave for the case of $\beta$-methyl- $\beta$-nitrostyrene is shown, but all compounds exhibit the same behaviour. As can be seen, when the $\mathrm{pH}$ is increased, the decrease in the main reduction wave is accompanied at more negative potentials by an increase in another wave. At sufficiently high $\mathrm{pH}$ values the height of this wave reaches a value corresponding to a three-electron process. The sum of these two waves remains constant and corresponds to a four-electron process. This behaviour is in accord with the following mechanism:

$$
\begin{aligned}
\mathrm{R}_{1}-\phi-\mathrm{CH}=\mathrm{CR}_{2}-\mathrm{NO}_{2}+\mathrm{e}^{-} \Leftrightarrow \mathrm{R}_{1}-\phi-\mathrm{CH}=\mathrm{CR}_{2}-\mathrm{NO}_{2}{ }^{-}- \\
\mathrm{R}_{1}-\phi-\mathrm{CH}=\mathrm{CR}_{2}-\mathrm{NO}_{2}^{-}-+3 \mathrm{e}^{-}+4 \mathrm{H}^{+} \\
\rightarrow \mathrm{R}_{1}-\phi-\mathrm{CH}=\mathrm{CR}_{2}-\mathrm{NHOH}+\mathrm{H}_{2} \mathrm{O}
\end{aligned}
$$

Similar behaviour has been observed when nitroaromatic compounds are reduced in the presence of added surfactant, or organic solvent in a basic medium [3034]. However, in the case of the derivatives of nitrostyrene, neither addition of surfactant nor organic solvent was necessary to observe the shifting of the main wave. This behaviour was not reported in previous work concerning $\beta$-nitrostyrene [21,22].

On the other hand, for all the compounds studied, it was possible to observe a small secondary polarographic wave (or peak) that occurs at more negative potentials in acidic media $(\mathrm{pH}<4)$, corresponding to the reduction of protonated hydroxylamine according to the following reaction:

$$
\begin{aligned}
\mathrm{R}_{1}-\phi-\mathrm{CH}=\mathrm{CR}_{2}-\mathrm{N}^{+} \mathrm{H}_{2} \mathrm{OH}+2 \mathrm{H}^{+}+2 \mathrm{e}^{-} \\
\rightarrow \mathrm{R}_{1}-\phi-\mathrm{CH}=\mathrm{CR}_{2}-\mathrm{N}^{+} \mathrm{H}_{3}+\mathrm{H}_{2} \mathrm{O}
\end{aligned}
$$

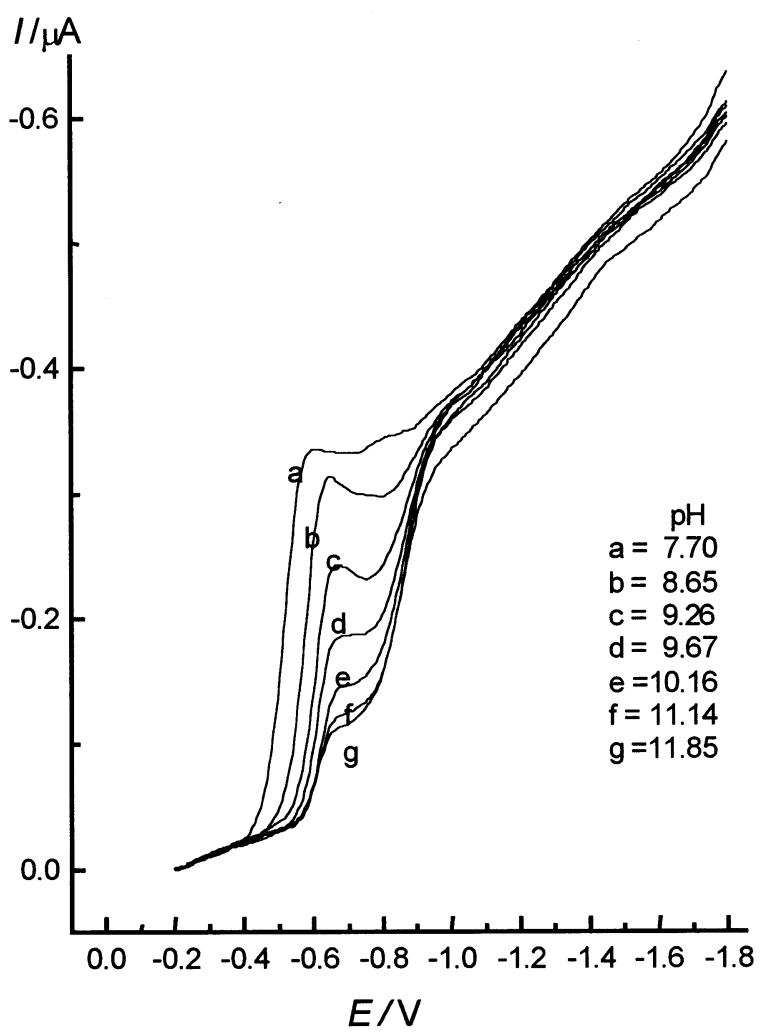

Fig. 5. Tast polarograms showing the splitting of the $\beta$-methyl- $\beta$-nitrostyrene at alkaline $\mathrm{pH}$. 


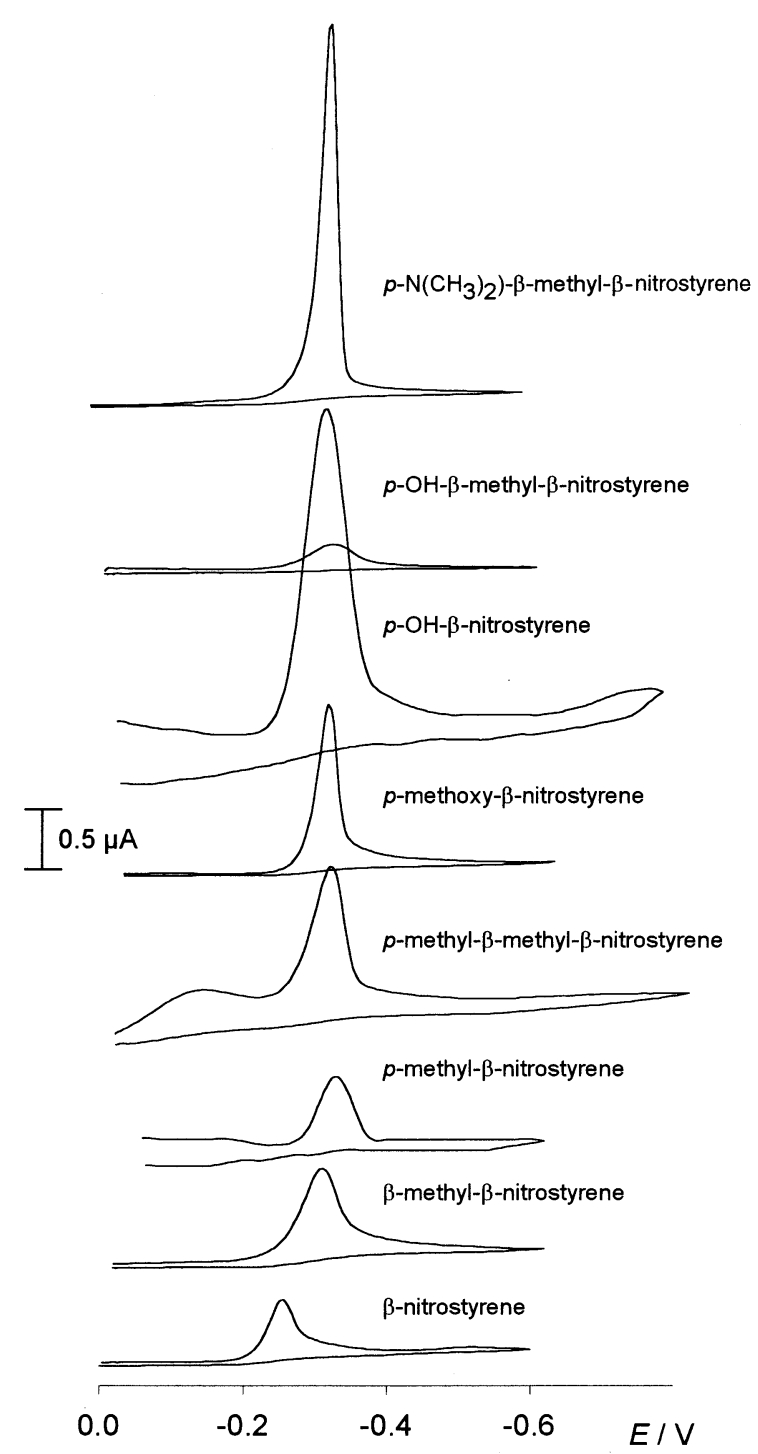

Fig. 6. Cyclic voltammograms of several $\beta$-nitrostyrene derivatives in aqueous media, $\mathrm{pH} 4$; sweep rate, $0.08 \mathrm{~V} \mathrm{~s}^{-1}$.

\subsection{Cyclic voltammetry}

All compounds produced a very well-defined and irreversible sharp peak at all $\mathrm{pH}$ values studied in aqueous media (Fig. 6). This peak corresponds to the above-described main peak (or wave) seen by differential pulse (or tast) polarography and is due to the four-electron, four-proton reduction producing the corresponding hydroxylamine derivative (Eq. (1)). The irreversible peak is pH-dependent (Fig. 7(a)) and from the sharp shape of the voltammograms an adsorption effect seems likely. However, from the dependence of peak current on sweep rate (Fig. 7(b)), it is possible to conclude that the process follows mixed diffusion-adsorption control, since the experimentally obtained slopes $\mathrm{d} \log I_{\mathrm{p}} / \mathrm{d} \log v$ have values between 0.5 and 1 [35]. For cyclic voltammetric experiments in aqueous alkaline media, it was not possible to observe the splitting of the signals observed by polarographic techniques. Consequently, the nitro radical anion/nitro reduction couple was not seen in aqueous media. However, in $100 \%$ DMF it is possible to observe a very well defined couple for all the nitrostyrene derivatives. In Fig. 8, the cyclic voltammograms of $\beta$-nitrostyrene at different sweep rates are shown. From these results it is possible to conclude that in aprotic media the process is diffusion controlled, since the slopes of plots of $\log I_{\mathrm{p}}$ versus $\log v$ have values close to 0.5 . Furthermore, the results in Fig. 8 show that as the scan rate increased, the current ratio, $I_{\mathrm{p}, \mathrm{a}} / I_{\mathrm{p}, \mathrm{c}}$ increased towards unity, typical behaviour for an irreversible chemical reaction following a charge-transfer step, i.e. the EC process. The couple is due to the monoelectronic reduction of the
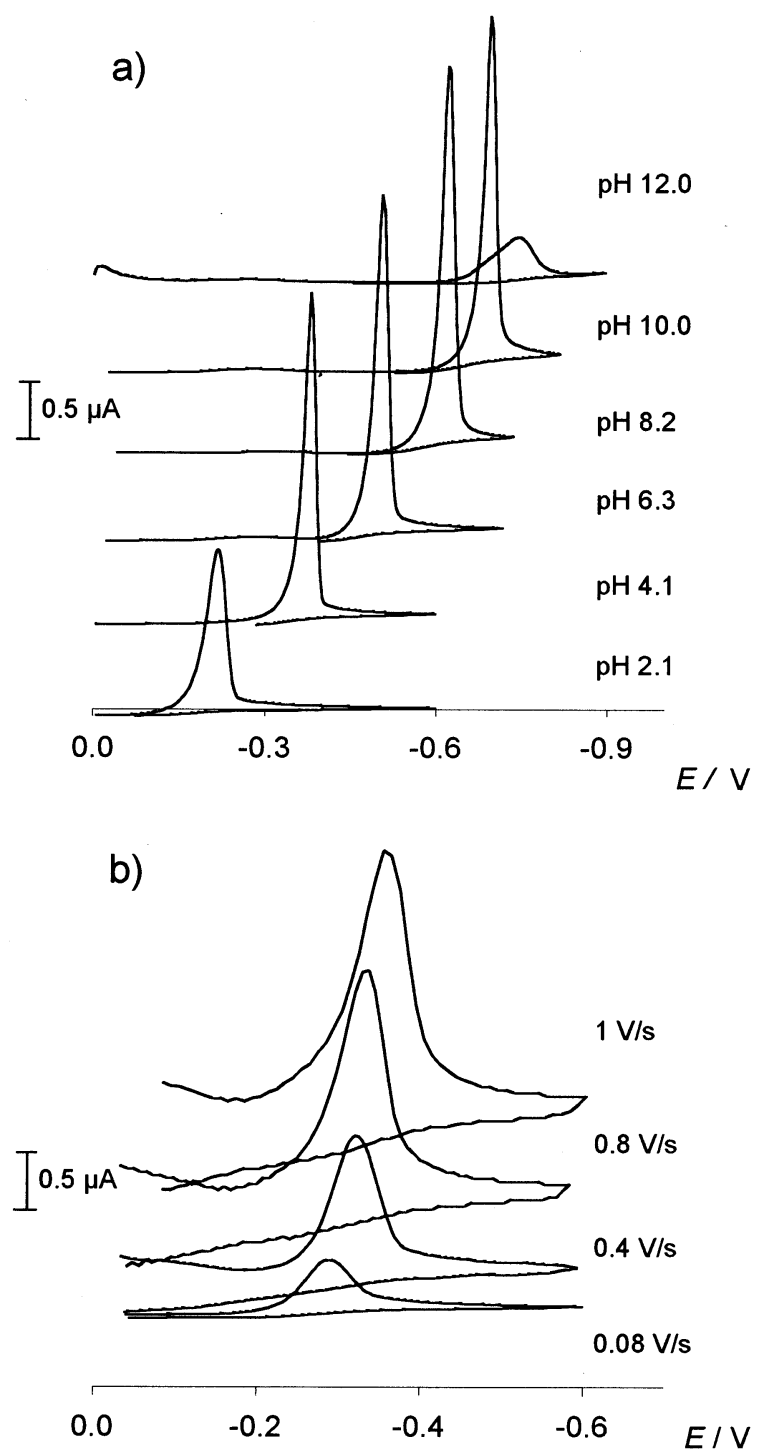

Fig. 7. Cyclic voltammograms of (a) $1 \mathrm{mM} p-\mathrm{N}\left(\mathrm{CH}_{3}\right)_{2}-\beta$-methyl- $\beta$-nitrostyrene solution at different $\mathrm{pH}$ values and $0.08 \mathrm{~V} \mathrm{~s}^{-1}$; (b) $1 \mathrm{mM}$ $\beta$-methyl- $\beta$-nitrostyrene solution at different sweep rates and $\mathrm{pH} 4.09$. 


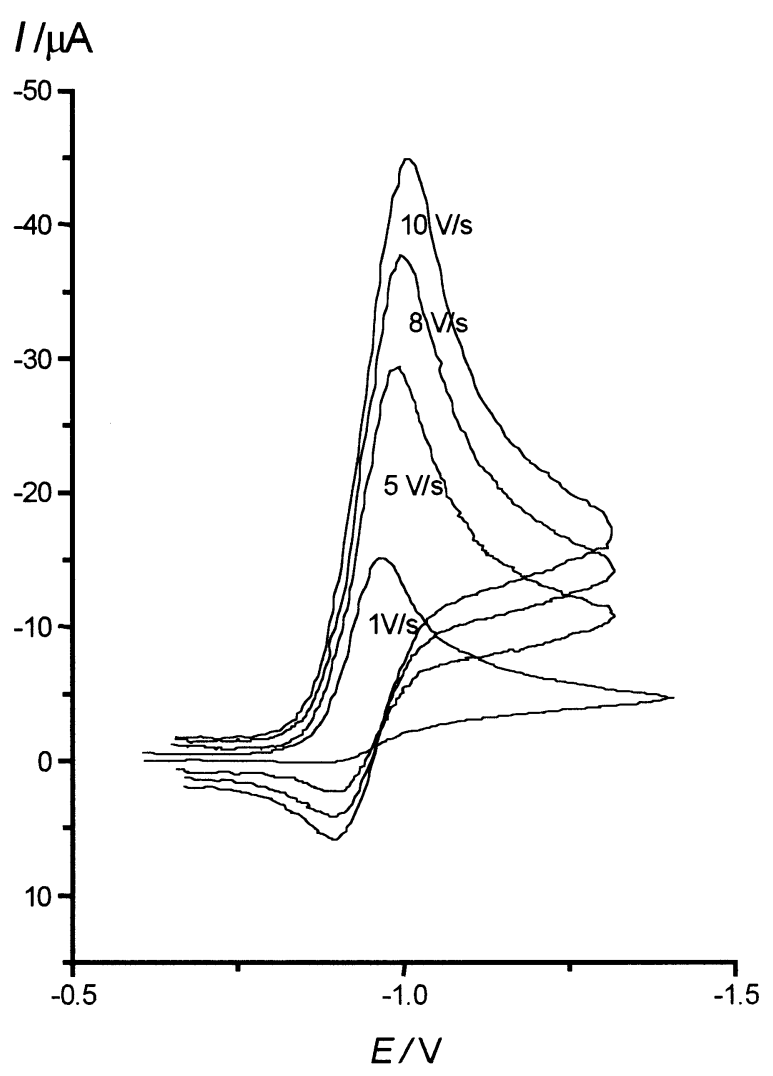

Fig. 8. Cyclic voltammograms of $1 \mathrm{mM}$ of $\beta$-nitrostyrene solution in $0.1 \mathrm{M}$ TBAP, $100 \%$ DMF, at different sweep rates.

nitro group in order to produce the nitro radical anion. In aqueous media the nitro radical anion is very unstable and consequently this couple was not observed.

\subsection{Substituent effects}

The study of substituent effects is based on shifts of half-wave potentials (Table 1). These half-wave potentials were measured under exactly the same experimental conditions. We have compared half-wave potentials under conditions where they are independent of $\mathrm{pH}$, i.e. $\mathrm{pH} 10$; however, the same conclusions are valid for the entire $\mathrm{pH}$ range. Furthermore, the $\alpha n$ values remain practically constant throughout the reaction series studied. Our discussion is focused mainly on the following structural effects for the nitrostyrene derivatives: (a) substitution of $\mathrm{H} \beta$ with a methyl group and (b) substitution at the para position on the aromatic ring.

First, we can discuss the effect of the substitution of the $\beta$-proton by a methyl group on the ethylenic moiety. From the half-wave potential values in Table 1, we observe that in all cases the $\beta$-methyl- $\beta$-nitrostyrene derivatives are reduced at more negative potentials than the corresponding $\beta$-nitrostyrene derivatives. Consequently, the reduction potential is sensitive to the substitution of the $\beta$-proton by a methyl group. It shifts several tens of millivolts towards more negative poten- tials on going from $\beta$-nitrostyrene to $\beta$-methyl- $\beta$-nitrostyrene derivatives. The observed differences can be ascribed to the lack of coplanarity of the molecules when $\beta$-methyl substitution occurs. According to AM1 calculations of minimum energy conformations and rotational barriers around the $\mathrm{C} 1-\mathrm{C} \alpha$ bond [27], $\beta$-nitrostyrenes are planar and $\beta$-methyl- $\beta$-nitrostyrenes display an angle of $45^{\circ}$ between the ethylenic and aromatic planes. The distortion of the coplanar arrangement in nitrostyrenes decreases the resonance interaction between the electroactive nitro group and the aromatic ring, and the observed shift towards negative potentials corresponds to this decrease. The validity of this assumption was also verified by comparing the contribution of the resonance effects from spectroscopic studies [27].

Second, we can discuss the effect that substitution at the para position of the aromatic ring has on the electroactivity of the nitro group. As can be seen from the half-wave potentials in Table 1, an increase in the electron-donor properties of the substituent at the para position increases the magnitude of the reduction potential, meaning that the reduction of the nitro group requires more energy to occur. This effect is about twice as important in the $\beta$-nitrostyrenes as in the $\beta$-methyl- $\beta$-nitrostyrenes, due to the decrease in conjugation with the increase in the $\mathrm{C} 1-\mathrm{C} \alpha$ torsion angle.

According to the previously described molecular-orbital calculations [27], these molecules have two barriers: the electronic barrier, associated with the loss of conjugation when the system loses planarity, and the steric barrier, which arises from the interaction of the methyl substituent at $\mathrm{C} \beta$ with the ortho aromatic protons. $\beta$-nitrostyrenes are planar with only the electronic barrier and $\beta$-methyl- $\beta$-nitrostyrenes have the two barriers described. In Fig. 9 the correlation between the calculated electronic barrier (as reported in Ref. [27]) and the half-wave potentials, in both series, are shown. The linearity obtained confirms the validity of our assumptions about the relevance of the electronic and steric effects on the nitro reduction of this family of nitrostyrenes. In previous work [27], similar behaviour was reported between the calculated electronic barrier and the double-bond stretching frequency of the ethylenic bond.

Finally, for the substituent study, the $E_{1 / 2}$ values are plotted against Hammett normal $\sigma_{\mathrm{p}}$ substituent constants [36] at $\mathrm{pH}$ 10. Linear relations with specific reaction constants of $\rho=4.78$ ( $\beta$-nitrostyrenes) and $\rho=4.37$ ( $\beta$-methyl- $\beta$-nitrostyrenes) were found (Fig. $10)$. From these values it is concluded that in all the cases studied the reduction proceeds via the same mechanism. The existence of a correlation between electrochemical data and structural parameters derived from homogeneous reaction indicates that adsorption is not the predominant factor governing the electrochemical 
- $\beta$-nitrostyrenes

- $\beta$-methyl- $\beta$-nitrostyrenes

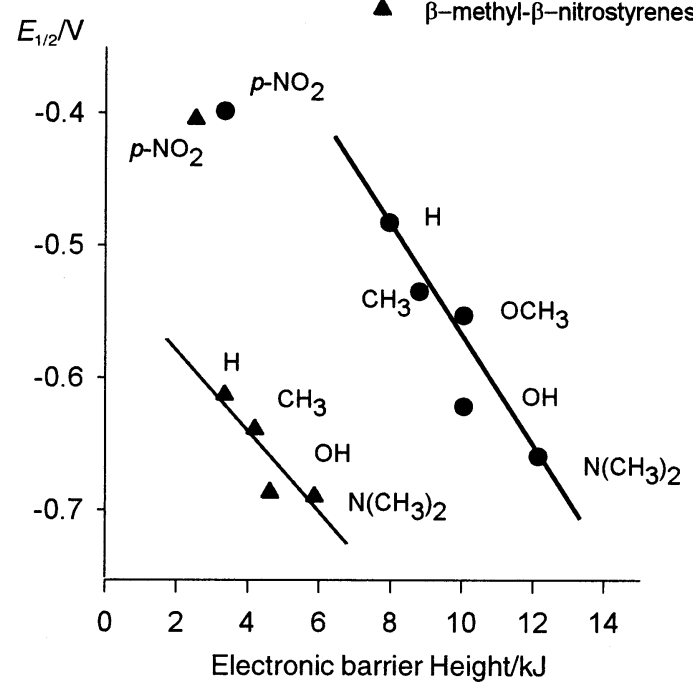

Fig. 9. Correlation between the calculated electronic barrier and the half-wave potentials of the nitro reduction in $\beta$-nitrostyrene and $\beta$-methyl- $\beta$-nitrostyrene derivatives.

behaviour of these nitrostyrene derivatives. Thus, the validity of correlations based on linear Gibbs energy relationships demonstrates that the electrochemical behaviour of these derivatives depends primarily on molecular structure and electron-density distribution in a way similar to rates and equilibrium of homogeneous chemical reactions. Specifically, the electrochemical behaviour of nitrostyrene derivatives depends on electrondensity distribution in the nitrovinyl group. Furthermore, these correlations should predict the $E_{1 / 2}$ of any nitrostyrene derivative.

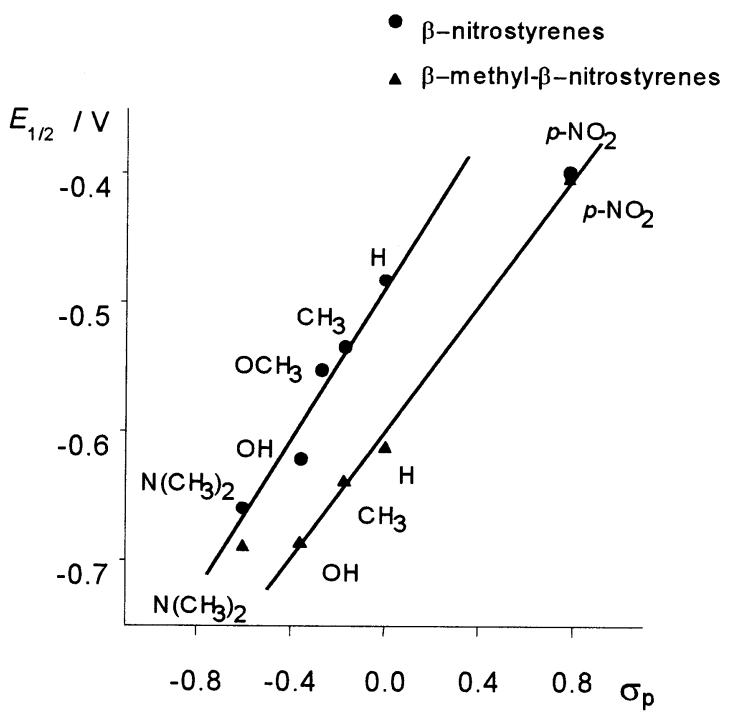

Fig. 10. Dependence of the half-wave potentials for the reduction of para-substituted $\beta$-nitrostyrene and $\beta$-methyl- $\beta$-nitrostyrene derivatives on the Hammett normal $\sigma_{\mathrm{p}}$ substituent constants.
In conclusion, this study shows that some correlations can be performed between electrochemical, spectroscopic, and structural parameters of the $\beta$-nitrostyrene derivatives. As the cytotoxicity of these substances has been correlated with the electrophilicity and the Hückel bond index of the nitrovinyl bond [7-9], the correlations obtained are an important tool that could be used in studies concerning the biological activity of these compounds.

\section{Acknowledgements}

We wish to thank the DID of the University of Chile and FONDECYT (Project 8970023) for financial support. We also want to thank Professor H. Lund for the bibliography.

\section{References}

[1] E.W. Bousquet, J.E. Kirby and N.E. Searle, US Patent 2335384 (November 30, 1943).

[2] P.W. Brian, J.F. Grove, J.C. McGowan, Nature 158 (1946) 876.

[3] J.C. McGowan, P.W. Brian, H.G. Hemming, Ann. Appl. Biol. 35 (1948) 25.

[4] J.R. Garbow, B.J. Gaede, J. Agric. Food-Chem. 38 (1990) 996.

[5] J.C. Doré, L. Montagnier, C. Viel, Chim. Thérap. 6 (1971) 167.

[6] L. Montagnier, E. Bisagni, J.D. Bouzat, J. Gruest, P. Marquet, J.J. Pepin, C. Rivalle, Chim Thérap. 6 (1971) 186.

[7] R. Cavier, I. Allade, P. Bouvier, R. Colau, J.C. Doré, C. Viel, Ann. Pharm. Franc. 36 (1978) 607.

[8] J.C. Doré, C. Viel, Chim.Thérap. 7 (1972) 214.

[9] J.C. Doré, O. Chalvet, C. Viel, Eur. J. Med. Chem.-Chim. Thérap. 11 (1976) 451.

[10] C.Y. Wang, B.C. Behrens, M. Ichikawa, G.T. Bryan, Biochem. Pharmacol. 23 (1974) 3395.

[11] J.J. Kamm, J.R. Gillette, Life Sci. 4 (1963) 254.

[12] D.R. Feller, M. Morita, J.R. Gillette, Biochem. Pharmacol. 20 (1968) 203.

[13] J.R. Gillette, J.J. Kamm, H.A. Sasame, Mol. Pharmacol. 4 (1968) 541.

[14] K. Tatsumi, H. Yamada, H. Yoshimura, Y. Kawazoe, Arch. Biochem. Biophys. 213 (1982) 689.

[15] H. Lund, in: H. Lund, M. Baizer (Eds.), Organic Electrochemistry; Chapter III, 3rd edition, Marcel Dekker, New York, 1990.

[16] B. Kastening, in: P. Zuman, L. Meites, I.M. Kolthoff (Eds.), Progress in Polarography, vol. 3, Wiley, New York, 1972.

[17] E. Laviron, R. Meunier-Prest, R. Lacasse, J. Electroanal. Chem. 375 (1994) 263.

[18] J.A. Squella, M. Huerta, S. Bollo, H. Pessoa, L.J. Nuñez-Vergara, J. Electroanal. Chem. 420 (1997) 63.

[19] A. Cyr, P. Huot, G. Belot, J. Lessard, Electrochim. Acta. 35 (1990) 147.

[20] C. Karakus, P. Zuman, J. Electroanal. Chem 396 (1995) 499.

[21] M. Masui, H. Sayo, Pharm. Bull.(Tokyo) 4 (1956) 332.

[22] L. Holleck, D. Jannakoudakis, Z. Naturforsch. B 16 (1990) 396.

[23] W.F. Reynolds, A. Gomes, A. Maron, D.W. MacIntyre, A. Tanin, G.K. Hamer, I.R. Peat, Can. J. Chem. 61 (1983) 2376.

[24] S. Datta, A. De, S. Prasad, C. Medhi, A.K. Chakravarty, J.S. Brunskill, S. Fadoujou, K. Fish, J. Chem. Soc. Perkin Trans. II (1988) 1599. 
[25] C.D. Slater, C.N. Robinson, R. Bies, D.W. Bryan, K. Chang, A.N. Hill, W.H. Moore, T.J. Otey, M.L. Poppelreiter, J.R. Reisser, G.E. Steblein, V.P. Waddy, W.D. Wilkinson, W.A. Wray, J. Org. Chem. 50 (1985) 4125.

[26] D.A. Happer, B.E. Steenson, J. Chem. Soc. Perkin Trans II (1988) 19.

[27] R.E. Clavijo, R. Araya-Maturana, B.K. Cassels, B. WeissLopez, Spectrochim. Acta Part A 50 (1994) 2105.

[28] S. Kauffman, Tesis de Licenciatura, Facultad de Ciencias, Universidad de Chile, 1978.

[29] D.E. Worral, L. Cohen, J. Am. Chem. Soc. 66 (1944) 842.
[30] G. Pezzatini, R. Guidelli, J. Electroanal. Chem. 102 (1979) 205.

[31] J. Stradins, I. Kravis, J. Electroanal. Chem. 65 (1975) 635.

[32] B. Kastening, L. Holleck, J. Electroanal. Chem. 27 (1970) 355.

[33] L.J. Núñez-Vergara, S. Bollo, A. Alvarez, J.A. Squella, M. Blazquez, J. Electroanal. Chem. 345 (1993) 121.

[34] L.J. Núñez-Vergara, F. García, M. Dominguez, J. de la Fuente, J.A. Squella, J. Electroanal. Chem. 381 (1995) 215.

[35] D.K. Gosser, Cyclic Voltammetry Simulation and Analysis of Reaction Mechanisms, Chapter 2, VCH, New York, 1994.

[36] C.G. Swain, E.C. Lupton, J. Am. Chem. Soc. 90 (1968) 4328. 